\title{
Challenges in Implementing the Ecosystem Approach: Lessons Learned
}

\author{
David Langlet and Rosemary Rayfuse
}

\section{1 \\ Introduction}

We began this book, in Chapter 1, by suggesting that the need for an ecosystem approach to the management of ocean resources seemed almost intuitive, in theory, but that in practice its effective implementation might be anything but. The reason for such difficulty was, we posited, a logical result of the many and varied complexities inherent not only in natural ecosystems, but also in the legal and institutional (eco)systems established for the management of those resources. Despite these complexities, however, the ecosystem approach is increasingly embedded in the context of marine management. Thus, a firm understanding of the legal and institutional challenges associated with its implementation is needed. The objective of this book has been to provide a range of analyses of the various manifestations of the ecosystem approach in practice, focusing primarily, though not exclusively, on the European context.

In this, concluding chapter, we draw on the various perspectives and experiences discussed in the preceding chapters, with a view to identifying common themes and challenges as well as distinctive features of the understanding and operationalization of the ecosystem approach to ocean management in the EU and beyond. We highlight important insights and identify remaining challenges to the effective operationalization of the approach, both in terms of improving its practical implementation, and in terms of further research needs.

The first important, albeit not original, insight is essentially a simple truism; the 'ecosystem approach' is a challenging concept. Indeed, its very meaning remains contested and its effective implementation is complex, confusing

(C) DAVID LANGLET AND ROSEMARY RAYFUSE, 2019 | DOI:10.1163/9789004389984_015 This is an open access chapter distributed under the terms of the prevailing CC-BY-NC License at the time of publication. 
and difficult. ${ }^{1}$ Obvious challenges relate to the scientific complexity inherent in the approach, which requires the integration of different fields of scientific knowledge as well as the constant need for the acquisition of up to date and improved data on natural and social systems alike. ${ }^{2}$ Beyond the scientific challenges, however, ascertaining the managerial objectives of the ecosystem approach is far from easy, particularly given the varying and different meanings ascribed to the approach by different actors and interests. ${ }^{3}$

This managerial challenge is starkly illustrated in the EU context, where reference to the ecosystem approach is often contained in legislation but no definition of the term is provided. ${ }^{4}$ Indeed, a lack of a clear and coherent understanding of what the approach entails in terms of management measures can be seen across all the main pieces of EU marine legislation. ${ }^{5}$ Not surprisingly, this lack of coherence has resulted in considerable heterogeneity in the manner in which the ecosystem approach has been understood and operationalised by the individual Member States in specific contexts such as in maritime spatial planning (MSP) processes. ${ }^{6}$

Adding to the confusion, there is no singular, definitive articulation of the concept. Rather, varying articulations exist, with some speaking of the 'ecosystem approach', while others refer to the concept of 'ecosystem-based management', and still others to the 'ecosystem approach to management'. These various formulations are sometimes used interchangeably, while at other times they are intentionally invoked as having distinct connotations. ${ }^{7}$ 'Ecosystem approach to management', in particular, is often invoked to reflect the fact that what is to be managed are human interactions with the ecosystem and

1 Vito De Lucia, 'Competing Narratives and Complex Genealogies: The Ecosystem Approach in International Environmental Law' (2015) 27 Journal of Environmental Law 91.

2 As noted by Fluharty, 'in order to make ecosystem science more relevant in decision-making it is necessary to know more about what people value and how they behave with respect to the marine environment.' David Fluharty in $\mathrm{Ch} 12$, 373. On the need for marine science to encompass and integrate both natural and social science perspectives, see Till Markus and others, 'Disciplinary diversity in marine sciences: the urgent case for an integration of research' (2018) 75 ICES Journal of Marine Science 502.

3 De Lucia (n 1) 100.

4 In EU law, the ecosystem approach is only defined in the CFP regulation, and even then, there is a mix of the approach as such and the approach as the objective. Luc van Hoof, 'Fisheries management, the ecosystem approach, regionalisation and the elephants in the room' (2015) 6o Marine Policy 20, 21.

5 Aron Westholm in Ch 4.

6 Michael Gilek, Fred Saunders, and Ignè Stalmokaitè in Ch 6.

7 KA Waylen and others, 'The Need to Disentangle Key Concepts from Ecosystem-Approach Jargon' (2014) 28 Conservation Biology 1215. 
not the ecosystem itself. ${ }^{8}$ This may, of course, be a more accurate reflection of the anthropocentric nature of marine resource governance in general. That it is human interactions being managed, and not the ecosystem itself, might, however, be considered obvious. Thus, the human element is arguably already implicit in other articulations of the concept as well.

In a generic sense, the term 'ecosystem approach' generally implies a level of systems thinking and a link between management structures and ecology, including a consideration of the interaction between natural systems and human systems. ${ }^{9}$ In most cases the relevant question may, in fact, be which formulation of the ecosystem approach concept more accurately meets the needs of the particular context or the particular task at hand, ${ }^{10}$ rather than what the ecosystem approach means as a general concept. As noted by Kidd, a mix of governance approaches is also likely to be beneficial. ${ }^{11}$ This is not to suggest that a lack of conceptual coherence or clarity may not present its own difficulties, ${ }^{12}$ but rather to suggest that different contexts may require different conceptualisations and the application of different, individualised considerations. Thus, the diversity of contexts - natural as well as social - in which an ecosystem approach is prescribed and pursued, renders the articulation of predetermined measures both unrealistic and unhelpful. ${ }^{13}$ In this respect, general principles, such as the Malawi Principles for the ecosystem approach, ${ }^{14}$ are more useful in providing an overarching frame of understanding as to what the approach requires. These general principles can then be supplemented by practical experience of the problems encountered and the lessons learned (in terms of fruitful thinking and action) in implementing the ecosystem approach in specific situations. As both the chapters in this book and broader literature demonstrate, ${ }^{15}$ such experiences, or case studies, may be context specific, but

\footnotetext{
8 David Fluharty in $\mathrm{Ch} 12$.

$9 \quad \operatorname{van} \operatorname{Hoof}(\mathrm{n} 4) 22$.

10 De Lucia (n 1 ) 24.

11 Sue Kidd in $\mathrm{Ch}_{5}$.

12 For examples see Collins Odote in $\mathrm{Ch}$ 13. Fluharty points to the problems that follow from the absence a clear or formally defined view of what marine ecosystem-based management is to achieve. Fluharty in $\mathrm{Ch} 12$.

13 In a similar vein Murawski finds it 'impossible to articulate a single set of indicators applicable in all situations' for judging the success of ecosystem based management. Steven A Murawski, 'Ten myths concerning ecosystem approaches to marine resource management' (2007) 31 Marine Policy 681, 686.

14 Submission by the Governments of the Netherlands and Malawi, Report of the Workshop on the Ecosystem Approach, 28 January 1998, UNEP/CBD/COP/4/Inf.9, 7.

15 See inter alia, David C Smith and others, 'Implementing marine ecosystem-based management: lessons from Australia' (2017) 74 ICES Journal of Marine Science 1990.
} 
they may nevertheless provide guidance or inspiration for application in other situations.

Admittedly, fully accounting for and structuring management measures around a comprehensive understanding of an ecosystem and its dynamics is, in many cases, practically impossible. Ecosystems are multidimensional, dynamic and interlinked and often lack clear spatial or biological delimitations. Comprehensive understandings of social structures and processes are also difficult to achieve, given their tendencies to complexity and to change over time. When the complexities of the two systems - natural and social - are combined, the result is almost utterly incomprehensible. Thus, to effectively implement an ecosystem approach in any meaningful manner, both systems must be defined in such a way as to render them manageable. To that end, geographic areas and institutional responsibility must be carefully delineated, and the required levels of detail of analysis and of management efforts must be carefully articulated. These choices should be thoroughly considered and based on the best available understanding of both the relevant ecological and social systems. In this respect, marine ecosystems can be seen as social constructs, ${ }^{16}$ and as the result of social processes - scientific, administrative, political - through which geographic areas are defined, desired ecosystem functions are articulated, and decisions are made regarding what to conserve, manage and monitor, in what manner, to what end, and for how long. ${ }^{17}$

In the light of the inherently demanding nature of the ecosystem approach, in terms of knowledge required and the nature and functioning of administrative structures, there is, in this context, a risk of the perfect becoming the enemy of the good. Achieving the perfect conditions for the ecosystem approach is often not a viable objective, either because it will lead to 'paralysis by analysis', i.e. the constant delaying of measures due to insufficient scientific understanding, or because of a lack of appropriate resources and legal-managerial structures for such a challenging task. Attempting to make do with what is available may be necessary. Obviously though, and as will be further discussed below, any attempt at applying the ecosystem approach must be premised on a willingness to re-evaluate and adjust management as understanding of the ecological and social systems at issue evolve.

Slater and Macdonald demonstrate that existing laws may provide an adequate basis for the implementation of an ecosystem approach even though the

16 Robert C Francis and others, 'Ten Commandments for Ecosystem-Based Fisheries Scientists' (2007) 32 Fisheries 217.

17 David Langlet, 'Scale, space and delimitation in marine legal governance - perspectives from the Baltic Sea' (2018) Marine Policy, accepted 24 September 2018, doi: 10.1016/ j.marpol.2018.09.027. 
approach is not specifically mandated. What is needed is a clear analysis of the legislative landscape in order to fully understand the impacts of non-oceans focused legislation and policies on the viability of measures intended to implement the ecosystem approach. ${ }^{18}$ The US experience, described by Fluharty, similarly illustrates the possibility of achieving an ecosystem approach in practice, even in the context of a highly fragmented legal framework in which the ecosystem approach is not recognised as an overarching or cross-sectoral principle, and where the desired spatial and sectoral coordination may be missing. ${ }^{19}$ It must, however, be admitted that lack of political interest in or support for ecosystem based measures will mean that necessary managerial mandates and resources are unlikely to be forthcoming. ${ }^{20}$

Within the EU, despite the lack of terminological clarity, the ecosystem approach has been embraced as a central theme in the major frameworks for marine governance: the Water Framework Directive (WFD), ${ }^{21}$ the Marine Strategy Framework Directive (MSFD), ${ }^{22}$ and the Maritime Spatial Planning Framework Directive (MSPD). ${ }^{23}$ These directives are specifically intended either to ensure the application of the ecosystem approach or to be implemented in a manner consistent with its application. ${ }^{24}$ When compared to the US situation, in particular, the EU model of legislating the ecosystem approach is more unequivocal and coherent, despite certain terminological confusion. Importantly, although essentially a top-down model, considerable room exists for considering regional or local conditions in certain circumstances.

\section{The Ecosystem Approach and the Role of Law}

In addition to the issue of terminology and what is actually meant by ecosystem approach, a recurring theme in discussions on the role of law as an instrument for the implementation of the ecosystem approach is the apparent conflict between the adaptivity required by the approach and the traditional

\footnotetext{
18 Anne-Michelle Slater and Alison MacDonald in Ch 9.

19 David Fluharty in Ch 12.

20 On the implications of lack of political support and of a general mandate for a crosssectoral ecosystem approach, see ibid.

21 Directive 2000/60/EC of the European Parliament and of the Council establishing a framework for Community action in the field of water policy [2000] OJ L 327/1.

22 Directive 2008/56/EC of the European Parliament and of the Council establishing a framework for community action in the field of marine environmental policy (Marine Strategy Framework Directive) [2008] OJ L 164/19.

23 Directive2014/89/EU establishing a framework for maritime spatial planning (MSPFD) [2014] OJ L 257/135.

24 See further Niko Soininen and Froukje Maria Platjouw in Ch 2.
} 
virtues of law, such as stability and legal certainty. ${ }^{25} \mathrm{~A}$ central challenge to successful marine governance is thus the need for legal structures capable of providing both stability and a high degree of flexibility and responsiveness to changes both in natural ecosystems and in our understanding of those systems, as well as the human behaviour that affects those systems. ${ }^{26}$ However, this perceived tension between stability and flexibility is not inevitable. As Soininen and Platjouw illustrate, while sometimes acting as a hindrance to adaptivity, principles such as legal certainty can, in fact, also serve as frameworks for driving environmental adaptive change. Actual outcomes of adaptive mechanisms are decided by policy choices and by scientific understandings of the relevant socio-ecological systems. ${ }^{27}$ In this respect, the authors suggest that all the main EU directives in this field, i.e. the WFD, the MSFD and the MSPD, have substantive capacity to support socio-ecological resilience, although through partly different instruments. ${ }^{28}$ Many of the features that typically represent an ecosystem approach have also been identified to already exist as, for example, in the international regime for the protection of the Baltic Sea. ${ }^{29}$ There may thus be less reason to see law as inherently problematic for adaptive management than is often assumed.

A further concern is that legal mechanisms providing for continuous learning and adjustment of policy measures, which are often associated with adaptive legal structures, may be at risk of losing (some of their) capacity to steer human activities. ${ }^{30} \mathrm{~A}$ core element of EU water and marine law is the establishment of quality standards that are to be achieved or maintained though legal measures. These include the notions of 'good surface water status' and the non-degradation rule of the WFD, and the 'good environmental status' of the MSFD. These standards, or rather the mechanisms though which they are to be achieved, i.e. primarily the adoption of programmes of measures that are regularly assessed and revised, have been criticised as being too weak to be effective. Nevertheless, in its recent case law, most notably the so called

25 de Sadeleer lists 'clarity, simplicity and certainty' as important attributes of modern law (which he subsequently contrasts with post-modern law). Nicolas de Sadeleer, Environmental Principles. From Political Slogans to Legal Rules (OUP 2002) 235.

26 Brita Bohman and David Langlet, 'Float or Sinker for Europe's Seas? - The Role of Law in Marine Governance', in Kristine Kern and Michael Gilek (eds), Governing Europe's Marine Environment: Europeanization of Regional Seas or Regionalization of EU Policies? (Ashgate 2015) 53 .

$27 \quad$ Niko Soininen and Froukje Maria Platjouw in Ch 2.

28 Ibid.

29 Brita Bohman in $\mathrm{Ch}_{3}$.

3o See e.g. Bohman and Langlet (n 26). 
Weser case, ${ }^{31}$ the EU Court of Justice has shown that even legal frameworks founded largely on the programmatic approach - essentially using regularly reviewed plans and programmes of measures as the primary tools for attaining environmental goals ${ }^{32}$ - can create distinct and enforceable obligations. ${ }^{33}$ However, since the MSFD and in particular the MSPD are less clear in setting out obligations, or do so on a much higher level of aggregation, ${ }^{34}$ it is unlikely that a similar development will be seen in relation to these directives.

\section{$4 \quad$ Geographical and Policy (In)consistency}

Further insights relate to the difficulties in adapting social structures such as legal frameworks and public institutions to the logic an characteristics of natural ecosystems. Although ecosystems, in themselves, constitute a delineation or delimitation of sections of the marine environment executed by humans for certain purposes and based on a certain level of understanding, ${ }^{35}$ making meaningful delimitations is often difficult due to the dynamic and interlinked nature of ecological and other natural processes. Nevertheless, it is often necessary to divide the large ecosystem(s) of the sea into smaller, more manageable, units. As Westholm notes, marine management is largely a question of delimitation. This delimitation necessitates numerous decisions concerning how to divide natural systems into appropriate units and how to match those units with appropriate institutions and other management structures. ${ }^{36}$ Clearly, governance structures should have the geographical scope and structure that best fits the ecosystem(s) at issue (as defined). This, in turn, may require existing social structures to be reconfigured, which may be challenging not only

31 Case C-461/13 Bund für Umwelt und Naturschutz Deutschland ECLI:EU:C:2015:433.

32 Niko Soininen and Froukje Maria Platjouw in Ch 2.

33 In this case, the court found that an EU Member State must refuse authorisation for any project that will result in deterioration of the status of the water body concerned or even jeopardise the attainment of good surface water status, unless the project is covered by a derogation. Case C-461/13 (n 31), para 50. On this so-called Weser case, se e.g. David Langlet and Said Mahmoudi, EU Environmental Law and Policy (Oxford University Press 2016) 228.

34 On the challenges of aggregation under the MSFD, see W Nikolaus Probst and Christopher P Lynam, 'Integrated assessment results depend on aggregation method and framework structure - A case study within the European Marine Strategy Framework Directive' (2016) 61 Ecological Indicators 871.

35 Robert C Francis and others (n 16).

36 Aron Westholm in $\mathrm{Ch}_{4}$. 
because of path dependency but also because those existing structures may have been designed to correspond with other societal logics and needs.

Equally challenging for the effective application of the ecosystem approach is achieving the political will necessary for the bridging of jurisdictional conflicts in areas with shared ecosystems. ${ }^{37}$ The politically demanding nature of such endeavours is clearly reflected in the vague or hortatory manner in which requirements for transboundary cooperation are typically phrased. This is so even with respect to cooperation within the EU where, despite the obvious logical necessity of strong coordination across boundaries in the marine spatial planning (MSP) context, most transboundary MSP initiatives are either merely voluntary in nature or take the form of pilot projects. ${ }^{38}$ Political commitment to the application of the ecosystem approach must therefore be present among all concerned States, something which is not assured. While this potential weakness would appear to be ameliorated by strong elements of supranational decision-making such as exist in the EU, even within the EU much is left to the will and priorities of individual Member States. The MSPD, in particular, affords much deference to national autonomy in decision-making, ${ }^{39}$ with MSP, as a site of governance, remaining primarily a national issue, reflecting different processes, institutional setups and historic contexts. ${ }^{40}$

While coordination between States is a challenge, even within States sectoral fragmentation and a lack of agencies with mandates corresponding to the physical ecosystems and social systems and processes with which they are linked poses challenges. ${ }^{41}$ Clearly, the locus of responsibility and competence within States for implementing ecosystem approach related measures, such as MSP, can have significant implications for successful implementation. This is true both in term of levels within the public administration and as regards the general policy focus of the organs entrusted with the relevant duty. ${ }^{42}$

The need for coordination is not, however, limited to intra - or even interEU coordination. Coordination between legal regimes at the regional and

37 Brita Bohman in $\mathrm{Ch}_{3}$.

38 Stephen Jay and others, 'Transboundary dimensions of marine spatial planning: Fostering inter-jurisdictional relations and governance' (2016) 65 Marine Policy 85.

39 David Langlet, 'Planning from the Margin - The European Union's Potential Role in Spatial Planning for Managing Activities in the Marine Arctic' (2018) 33 International Journal of Marine and Coastal Law 361.

40 Michael Gilek, Fred Saunders, and Ignè Stalmokaitè in Ch 6.

41 On the situation in Germany, see Eva Schachtner in Ch 11.

42 Aron Westholm in Ch 4. For a similar analysis, see Björn Hassler and others, 'Collective action and agency in Baltic Sea marine spatial planning: Transnational policy coordination in the promotion of regional coherence' (2018) 92 Marine Policy 138. 
global level is also necessary due, not only to geographical factors, but also to the fact that marine regulatory regimes, even when regional in nature, tend to deal with only some of the pressing issues relevant to the application of the ecosystem approach. By way of example, the Helsinki Convention for the Baltic Sea, ${ }^{43}$ the OSPAR Convention for the North Sea ${ }^{44}$ and the Barcelona Convention for the Mediterranean ${ }^{45}$ all lack mandates to regulate fisheries and (for the most part) shipping. Regulation of shipping is largely dealt with within the framework of the International Maritime Organisation (IMO) while fisheries policy in the $\mathrm{EU}$ is, in principle, the exclusive domain of the Union in the form of the Common Fisheries Policy (CFP). Integrating shipping and fisheries into comprehensive ecosystem management therefore requires cooperation between the different regimes. ${ }^{46}$ In the fisheries context, the CF P could be seen as an asset in relation to the ecosystem approach in that it should, in theory, guarantee the uniform application of ecosystem principles to the fishing sector. However, significant problems have been encountered with coordination efforts both between internal EU policy instruments and between the CFP and regional environmental agreements. For example, while fisheries policy is to 'be coherent with the Union environmental legislation, in particular with the objectives of achieving good environmental status by $2020^{\prime}, 47$ no specific requirements exist to ensure coherence between the CFP and the environmental objectives of the MSFD. Wakefield considers this 'failure to integrate environmental and fisheries policy' as preventing 'regeneration and sustainability of both fish stocks and wider ecosystems. 48

Although it is perhaps making a virtue of necessity, there may be some advantages to jurisdictional and policy diversity. Such diversity can allow for different approaches to be pursued and tested and experiences to be shared, thereby contributing to the potential for adaptive development of legal and policy frameworks. This presupposes, however, that functioning mechanisms for such exchanges are in place and that policymakers are open and responsive to the need for continued adjustments in the light of new knowledge. In the

43 Convention on the Protection of the Marine Environment of the Baltic Sea Area (Helsinki, 9 April 1992, into force 17 January 2000) 2099 UNTS 195.

44 Convention for the Protection of the Marine Environment of the North-East Atlantic (Paris, 22 September 1992, into force 25 March 1998) 32 ILM 1075.

45 Convention for the Protection of the Mediterranean Sea against Pollution (Barcelona, 16 February 1976, into force 12 February 1978) 1102 UNTS 27.

46 The objectives and main principles of the CPF are set out in Regulation (EU) No 1380/2013 of the European Parliament and of the Council on the Common Fisheries Policy ... [2013]

OJ L $354 / 22$.

47 Regulation 1380/2013, Article 2(5)j.

48 Jill Wakefield in Ch 10, 293. 
EU context, at least, this openness can, to some extent follow from the recurring revisions prescribed by EU law for maritime spatial plans as well as for programmes of measures under the MSPD and the WFD.

\section{5}

\section{Knowledge and Participation}

A further insight revealed in the chapters is that qualitative application of the ecosystem approach requires a deep and up-to-date understanding of the ecosystem(s) in issue. The need to capture ecosystem feedback across relevant scales makes the ecosystem approach information - and thus monitoring intensive. ${ }^{49}$ Indeed, closing the knowledge gaps on ecosystem functioning is likely to be a never-ending process, ${ }^{50}$ as is the need for continued understanding of the social systems with which the ecosystems interact as well as the relevant preferences and other factors that drive human behaviour in relation to the marine environment. ${ }^{51}$ In addition to monitoring and scientific research, closing the knowledge gap thus necessitates effective collaboration with a wide set of stakeholders, both as knowledge bearers and as actors whose participation and acceptance are often crucial for the successful implementation of management measures. In this respect, participation is fundamental to the ecosystem approach as both a knowledge acquisition process and as a means of ensuring the engagement of concerned actors, thereby enhancing the understanding and acceptance of policies and measures. Indeed, Zervaki identifies participation as the 'sine qua non for successful MSP projects' since effective marine spatial planning is dependent on public trust in its ability to balance various interests. ${ }^{52}$ This need for inclusiveness, both in terms of who to involve and in relation to what kinds of knowledge are needed, is, in fact, reflected in the Malawi Principles, according to which the ecosystem approach 'should involve all relevant sectors of society and scientific disciplines'.53

However, while participation is often key to successful, or even workable, management policies, it is not without is challenges. To begin with, there is the risk of economically stronger or more well-organized interests becoming

49 H Österblom and others, 'Making the ecosystem approach operational - Can regime shifts in ecological - and governance systems facilitate the transition?' (2010) 34 Marine Policy 1290, 1297.

5o Eva Schachtner in $\mathrm{Ch} 11$.

51 Österblom and others (n 49) 1297; David Fluharty in Ch 12.

52 Antonia Zervaki in $\mathrm{Ch} 8,233$.

53 Report of the Workshop on the Ecosystem Approach (n 14), Principle 12. 
overly dominant in participatory processes or structures, such as has occurred in the EU's fisheries advisory councils. ${ }^{54} \mathrm{~A}$ further challenge relates to the way in which science is to feed into relevant policy processes. As noted by Zervaki, 'cooperation between scientists and policymakers is not an easy one since they do not share a common working methodology or objectives'.55 Indeed, the nature of the scientific pursuit of knowledge is not easily squared with the pace and logic of policy processes. A similar situation can be discerned with regards to science and users of ecosystem resources. Gilek, Saunders and Stalmokaite show that fishers can feel excluded from policy processes, such as those involving the development of maritime spatial plans, because the language used by scientists is not accessible to them. They may also feel that their knowledge of the resource is not properly valued compared to the results of scientific studies. ${ }^{56}$ This brings to the fore the need to ensure that processes are truly inclusive in the sense that stakeholders can both understand the process as such, and the information provided, as well as feel that they have a genuine impact on the outcome of the process.

In reality, however, determining how and when to utilise local knowledge as a means of achieving conservation solutions is quite challenging. ${ }^{57}$ This is particularly so in the context of MSP processes where the application of the ecosystem approach has been found to be primarily concerned with ecological and economic values and trade-offs between the two. ${ }^{58}$ Gilek, Saunders and Stalmokaite go so far as to identify the need for a complementary 'Sociocultural Approach' (SA) to better address the manner in which 'issues such as participation, procedural justice, social inclusion and knowledge pluralism could be focussed and promoted in MSP. 59 Nevertheless, as the case study presented by Slater and Macdonald demonstrates, collaborative processes that are well designed and allowed to take time can yield very positive outcomes in terms of shared understandings of ecological and policy linkages and interactions, as well as reduce conflicts. ${ }^{60}$

54 Jill Wakefield in Ch 10.

55 Antonia Zervaki in Ch 8, 238.

56 Michael Gilek, Fred Saunders, and Ignè Stalmokaitè in Ch 6, 182.

57 Julia G Mason, Murray A Rudd and Larry B Crowder, 'Ocean Research Priorities: Similarities and Differences among Scientists, Policymakers, and Fishermen in the United States' (2017) 67 BioScience 418.

58 Michael Gilek, Fred Saunders, and Ignè Stalmokaitè in Ch 6.

59 Ibid., 189.

6o Anne-Michelle Slater and Alison MacDonald in Ch 9. 
In this context ocean literacy seems to offer an important contribution. ${ }^{61}$ Of course, enhanced knowledge of the vital and complex natural processes presented by the oceans, and their possibly even more complex interactions with social systems, will not do away with all resource conflicts and contestations regarding knowledge production. It may, however, enhance acceptance of the fact that management interventions, though often needed, are equally often imperfect, iterative processes. As Fluharty's review of the evolution of marine policy in the US reveals, considerably more is known about marine ecosystems than is generally applied when making management decisions. ${ }^{62}$ Increased understanding of the vital importance of the ocean and the complexities of its ecosystems may go some way towards remedying this.

Importantly, however, learning is not a one-way process. The scientific community - or communities - also have much to learn about how to use knowledge generated elsewhere, including by other scientific disciplines, ${ }^{63}$ and about how to communicate scientific findings and uncertainties in a comprehensible manner.

Humans as Part of the Ecosystem

Our final insight relates to the critical importance of understanding the role of humans within natural ecosystems. The Malawi Principles note, rather unsurprisingly, that management objectives for natural ecosystems are a matter of societal choice. ${ }^{64}$ The application of an ecosystem approach requires the acknowledgement of the importance of ecosystems and of the interactions between those and social systems, but it does not as such determine the outcome of management processes. Such processes may very well entail a balancing of environmental, economic and social objectives; an operation where the ecosystem approach as such may provide limited guidance. ${ }^{65}$

The important point here is that humans are not only decision makers in relation to ecosystems; humans are also, as biological entities, part of those systems. Indeed, it has been held that 'the most significant feature of [the ecosystem approach to management] is the understanding of humans as part of the ecosystem, where human activities are seen as an integral part

61 On ocean literacy, see Sue Kidd in $\mathrm{Ch} 5$.

62 David Fluharty in Ch 12. For a similar conclusion, see Murawski (n 13) 684.

63 On the need for interdisciplinary research as a basis for marine policy making, see Mason, Rudd and Crowder (n 57).

64 Report of the Workshop on the Ecosystem Approach (n 14), Principle 1.

65 Michael Gilek, Fred Saunders, and Ignè Stalmokaitė in Ch 6. 
of ecosystem processes and thus of the management of natural resources'. ${ }^{6}$ However, the inclusion of humans as an integral part of an ecosystem can lead to unintended and not entirely unproblematic consequences. For example, while humans may define ecosystems and 'natural' processes in a conceptual sense, we also form and transform ecosystems through both intentional and unintentional impacts. Indeed, the human ability to indelibly transform the natural world of which we are part is at the core of the much-discussed notion of the Anthropocene. ${ }^{67}$ Moreover, as noted by Bastmeijer, application of the ecosystem approach should ideally commence at a moment in time when ecosystems are pristine and healthy. ${ }^{68}$ While exceptions may exist, for example in the case of the deep sea-bed beyond national jurisdiction, such an opportunity is, however, rarely available in the context of marine governance efforts today. The ecosystem approach must thus be applied in such a way as to prevent further deterioration and even to engage in ecological restoration. ${ }^{69}$

When humans are seen as (natural or inevitable) parts of ecosystems, it thus becomes essential to have strong legal mechanisms in place to prevent overuse in the pursuit of short term interests. In this regard, Bastmeijer as well as Soininen and Platjouw warn of the dangers of leaving too much discretion to individual actors, including States, when it comes to the balancing of interests, ${ }^{70}$ because of the risk of giving "humans" too dominant a position in the ecosystem. ${ }^{71}$ The risk relates not only to short term or narrowly defined interests outweighing the longer and broader perspectives needed for sustainability, but also to the possibility of changes in human conceptions of what constitutes a 'pristine and healthy' ecosystem. Often referred to as the 'shifting baseline syndrome', the problem arises because each new generation of scientists - and indirectly also policymakers - is likely to have a different understanding of what constitutes, for example, 'primal abundance and diversity', thus prompting a gradual adjustment to ever more degraded ecosystems. ${ }^{72}$ Once a degraded state is accepted, the possibility of restoration or of imposing

66 Sara Söderström and Kristine Kern, 'The Ecosystem Approach to Management in Marine Environmental Governance: Institutional interplay in the Baltic Sea Region' (2017) 27 Environmental Policy and Governance 619, 621.

67 Paul J Crutzen, 'The "Anthropocene"' in Eckart Ehlers and Thomas Krafft (eds), Earth System Science in the Anthropocene (Springer 2006) 13.

68 Kees Bastmeijer in $\mathrm{Ch} 7$.

69 Ibid.

$70 \quad$ Kees Bastmeijer in $\mathrm{Ch}_{7}$, Niko Soininen and Froukje Maria Platjouw in $\mathrm{Ch} 2$.

71 Kees Bastmeijer in $\mathrm{Ch}_{7,216 .}$

72 Daniel Pauly, 'Anecdotes and the shifting baseline syndrome of fisheries' (1995) 10 Trends in Ecology and Evolution 430. 
responsibility for the damage will likely be lost, ${ }^{73}$ thereby providing a license to more generally degrade the ecosystem.

As illustrated in the context of the MSFD, the challenges of setting so-called 'threshold values', i.e. values that allow for an assessment of the quality level achieved for a particular assessment criterion, are great. Under the MSFD, the EU commission has recognized that the values shall reflect natural ecosystem dynamics, 'acknowledging that the ecosystem or parts thereof may recover, if deteriorated, to a state that reflects prevailing physiographic, geographic, climatic and biological conditions, rather than return to a specific state of the past. ${ }^{74}$ While perhaps an acknowledgment of an irrefutable fact, due both to purely natural processes and to the pervasive and continuous effects of human activities, this can also be seen as a pretext for accepting the continued degradation of ecosystems. However, the recognition of variability or relative indeterminacy, should not be allowed to justify the continued gradual degradation of the marine environment as the inevitable result of changing conditions. ${ }^{75}$ What is needed are instruments designed to meet ecosystem approach criteria which do not entail the same level of discretion. ${ }^{76}$

\section{$7 \quad$ Concluding Thoughts}

We end where we began, with an acknowledgement that the ecosystem approach is a compelling but complex concept. Its recognition as one of the widely accepted ocean governance approaches is evident from its inclusion in a long list of policy and legal documents at the national, regional and global level. Its application, however, remains contested and challenging. Analysis of its implementation in individual contexts can help shed light on both its content and on its normative effect. An important message is that good work in implementing the approach can be done even when the preconditions are far from perfect. Considering the challenges in both scientific and political terms, optimal conditions may never be forthcoming. Fortunately, the approach can be seen as a way of thinking that can be applied - although with varying rigour or impact - in most situations. Much more research and knowledge generation

\footnotetext{
73 Jill Wakefield in Ch 10.

74 Commission Decision (EU) 2017/848 [2017] OJ L 125/43, Art. 4 (1).

75 Brian Moss, 'The Water Framework Directive: Total environment or political compromise?' (2008) 400 Science of The Total Environment 32, 39.

76 Niko Soininen and Froukje Maria Platjouw in Ch 2.
} 
are indeed needed, both concerning ecological and social systems as well as their interactions, and much of this will, by necessity, be at least partly place and context specific. However, a key challenge often seems to be found in putting existing knowledge to good use. There are many examples of the application of the ecosystem approach - wholly or partly - from which to draw lessons or inspiration, although adjusting such knowledge and experience to the conditions of each context will require thoughtful consideration. Here iterative processes that allow for gradual adjustments as more understanding is gained are crucial. Promoting increased recognition of the fundamental importance of marine ecosystems as well as some understanding of their basic features and processes should also facilitate political support for engaging with challenges such as effective transboundary cooperation on marine ecosystembased management.

\section{Table of Authorities}

\section{Treaties}

Convention for the Protection of the Mediterranean Sea against Pollution (Barcelona, 16 February 1976, into force 12 February 1978) 1102 UNTS 27.

Convention on the Protection of the Marine Environment of the Baltic Sea Area (Helsinki, 9 April 1992, into force 17 January 2000) 2099 UNTS 195.

Convention for the Protection of the Marine Environment of the North-East Atlantic (Paris, 22 September 1992, into force 25 March 1998) 32 ILM 1075.

\section{EU Directives and Regulations}

Directive 2000/6o/EC of the European Parliament and of the Council establishing a framework for Community action in the field of water policy [200o] OJ L 327/1.

Directive 2008/56/EC of the European Parliament and of the Council establishing a framework for community action in the field of marine environmental policy (Marine Strategy Framework Directive) [2008] OJ L 164/19.

Regulation (EU) No 1380/2013 of the European Parliament and of the Council on the Common Fisheries Policy (...) [2013] OJ L 354/22.

Directive 2014/89/EU establishing a framework for maritime spatial planning (MSPFD) [2014] OJ L 257/135.

\section{Case Law}

Case C-461/13 Bund für Umwelt und Naturschutz Deutschland ECLI:EU:C:2015. 


\section{Bibliography}

\section{Books}

Langlet D and Mahmoudi S, EU Environmental Law and Policy (Oxford University Press 2016).

de Sadeleer N, Environmental Principles. From Political Slogans to Legal Rules (Oxford University Press 2002).

\section{Book Chapters}

Bohman B and Langlet D, 'Float or Sinker for Europe's Seas? - The Role of Law in Marine Governance', in Kern K and Gilek M (eds), Governing Europe's Marine Environment: Europeanization of Regional Seas or Regionalization of EU Policies? (Ashgate 2015) 53 .

Crutzen PJ, 'The "Anthropocene"' in Ehlers E and Krafft T (eds), Earth System Science in the Anthropocene (Springer 2006) 13.

\section{Journal Articles}

De Lucia V, 'Competing Narratives and Complex Genealogies: The Ecosystem Approach in International Environmental Law' (2015) 27 Journal of Environmental Law 91.

Francis RC and others, 'Ten Commandments for Ecosystem-Based Fisheries Scientists' (2007) 32 Fisheries 217.

Hassler B and others, 'Collective action and agency in Baltic Sea marine spatial planning: Transnational policy coordination in the promotion of regional coherence' (2018) 92 Marine Policy 138.

van Hoof L, 'Fisheries management, the ecosystem approach, regionalisation and the elephants in the room' (2015) 6o Marine Policy 20.

Jay S and others, 'Transboundary dimensions of marine spatial planning: Fostering inter-jurisdictional relations and governance' (2016) 65 Marine Policy 85.

Langlet D, 'Planning from the Margin - The European Union's Potential Role in Spatial Planning for Managing Activities in the Marine Arctic' (2018) 33 International Journal of Marine and Coastal Law 361.

Langlet D, 'Scale, space and delimitation in marine legal governance - perspectives from the Baltic Sea' (2018) Marine Policy, accepted 24 September 2018, doi: 10.1016/ j.marpol.2018.09.027.

Markus T and others, 'Disciplinary diversity in marine sciences: the urgent case for an integration of research' (2018) 75 ICES Journal of Marine Science 502.

Mason JG, Rudd MA and Crowder LB, 'Ocean Research Priorities: Similarities and Differences among Scientists, Policymakers, and Fishermen in the United States' (2017) 67 BioScience 418. 
Moss B, 'The Water Framework Directive: Total environment or political compromise?' (2008) 400 Science of The Total Environment 32.

Murawski SA, 'Ten myths concerning ecosystem approaches to marine resource management' (2007) 31 Marine Policy 681.

Österblom H and others, 'Making the ecosystem approach operational - Can regime shifts in ecological- and governance systems facilitate the transition?' (2010) 34 Marine Policy 1290.

Pauly D, 'Anecdotes and the shifting baseline syndrome of fisheries' (1995) 10 Trends in Ecology and Evolution 430.

Probst WN and Lynam CP, 'Integrated assessment results depend on aggregation method and framework structure - A case study within the European Marine Strategy Framework Directive' (2016) 61 Ecological Indicators 871 .

Smith DC and others, 'Implementing marine ecosystem-based management: lessons from Australia' (2017) 74 ICES Journal of Marine Science 1990.

Söderström S and Kern K, 'The Ecosystem Approach to Management in Marine Environmental Governance: Institutional interplay in the Baltic Sea Region' (2017) 27 Environmental Policy and Governance 619.

Waylen KA and others, 'The Need to Disentangle Key Concepts from EcosystemApproach Jargon' (2014) 28 Conservation Biology 1215. 